\title{
Expert controller in multi-variable System of Temperature and Humidity
}

\author{
Yinping $M a^{a^{*}}, Z u-y a n L u^{b}$ \\ a Jiangsu Maritime Institute, Nanjing 211170, Jiangsu, China \\ ${ }^{b}$ Nanjing University of Science and Technology, Nanjing, China \\ ${ }^{*}$ E-mail address: mayinping1989@126.com \\ ORCID numbers of authors: \\ 0000-0003-1127-1933 ${ }^{a}, 0000-0002-8734-0053^{b}$
}

Received date: July 2017

Accepted date: September 2017

\begin{abstract}
In order to ensure the humidity-and heat-resistance ability of the equipment, this paper, combined with the environment simulation test of an engineering equipment system, designs the control system of humidity-heat simulation test with S7300 as the control core. This paper analyzes the temperature and humidity model in laboratory, and applies the principle of the expert control to the system control algorithm to improve the control performance of the system, which shows the characteristics of lagging, nonlinearity, interactive coupling of temperature control and humidity control, etc.
\end{abstract}

Keywords: nonlinearity, interactive coupling, expert control system

\section{Introduction}

With the rapid development of China's industrial production and the improvement of military equipment, the requirements for product quality and reliability are getting steadily higher, especially military products. All the products have to undergo the strict environmental simulation test for acceptance before the mass production and army equipment. The humidity-heat alternative test is a "conventional" test method in the environmental simulation test, aiming to determine the adaptability of weaponry under high temperatures or high humidity conditions.

Weaponry in the hot and humid simulation environment assessment proposes rather strict requirement in accuracy of the temperature and humidity environment[1]. If applying the traditional PID control theory, it is difficult to precisely control the object of nonlinearity, large time delay, and uncertain mathematical model, because the traditional control theory and method are based on the precise model with integration and differentiation as the tool, while intelligent control shows greater adaptation for the complexity of the environment and control tasks[2-3].

Combined with the environment simulation test on an engineering equipment project, this paper designs the control system of heat-humidity alternative test with S7-300 as the control core, collecting signal and controlling equipment with sensors and actuators. The system adopts the expert control algorithm to realize the precise control over the temperature and humidity in the alternative test, thus ensure the capability of the equipment in heat- and humidity- resistance. 


\section{Analysis of Temperature and Humidity Control Model}

Before determining the control scheme for the temperature control system of the humidity-heat test, it is necessary to firstly analyze the humidity-heat mechanism, and obtain the inherent characteristic information of the system as much as possible. The humidity-heat laboratory has the main two parts -- temperature control and humidity control.

\subsection{Laboratory temperature object model}

The temperature in the laboratory is mixed and can be described by only one value, which is measured with a return thermometer, with the indoor temperature object model list according to the energy conservation:

$$
C_{\mathrm{v}} V \frac{d T_{h}}{d t}=Q_{\text {in }}-Q_{\text {out }}=\left(G_{\mathrm{a}} \rho C_{\mathrm{p}} T_{\mathrm{c}}+\mathrm{Q}_{\mathrm{n}}\right)-\left(G_{\mathrm{a}} \rho C_{\mathrm{p}} T_{\mathrm{h}}+\frac{T_{h}-T_{0}}{R}\right)
$$

where $C_{v}\left(\mathrm{~J} / \mathrm{m}^{3} .{ }^{\circ} \mathrm{C}\right)$ is volumetric heat capacity, $\mathrm{V}\left(\mathrm{m}^{3}\right)$ is volume of laboratory, $T_{\mathrm{h}}\left({ }^{\circ} \mathrm{C}\right)$ is temperature of return air inlet, $G_{\mathrm{a}}\left(\mathrm{m}^{3} / \mathrm{s}\right)$ is air output, $\rho\left(\mathrm{kg} / \mathrm{m}^{3}\right)$ is air density, $C_{p}\left(\mathrm{~J} / \mathrm{kg}^{\circ} \mathrm{C}\right)$ is specific heat at constant pressure, $T_{\mathrm{c}}\left({ }^{\circ} \mathrm{C}\right)$ is temperature of air outlet, $\mathrm{Q}_{\mathrm{n}}(\mathrm{J} / \mathrm{s})$ is heat dissipating capacity, $T_{0}\left({ }^{\circ} \mathrm{C}\right)$ is outdoor temperature, $\mathrm{R}$ is thermal resistance of envelope.

Do not consider the prototype and other cooling, the external heat dissipation in the test room is the circulating fan and the indoor lighting, about $70 \%$ of the circulating fan power $\left(43 \mathrm{~kW}^{*} 2\right)$ transforming into heat dissipation in the room, that is, circulating fan cooling $Q_{1}=43 \times 2 \times 70 \% \approx 60 \mathrm{~kW}$ ; similarly, lighting $Q_{2}=18 \times 25 \%=4.5 \mathrm{~kW},{ }^{2}$ being approximately constant.

$$
\begin{array}{cc}
T \frac{\mathrm{d} T_{\mathrm{h}}}{\mathrm{dt}}+T_{\mathrm{h}}=K\left(T_{\mathrm{c}}+T_{\mathrm{f}}\right), & T=\frac{C_{\mathrm{v}} V}{G_{\mathrm{a}} \rho C_{\mathrm{p}}+R} \\
K=\frac{G_{\mathrm{a}} \rho C_{\mathrm{p}}}{G_{\mathrm{a}} \rho C_{\mathrm{p}}+\frac{1}{R}}, & T_{\mathrm{f}}=\frac{Q_{\mathrm{n}}+\frac{T_{0}}{R}}{G_{\mathrm{a}} \rho C_{\mathrm{p}}}
\end{array}
$$

In which $\mathrm{T}$ refers to time constant, $\mathrm{K}$ refers to amplification constant, $\mathrm{T}_{\mathrm{f}}$ is used to convert the interference to the variation of Outlet temperature.

The transfer function of the temperature $T_{\mathrm{h}}$ of the return air intlet and the temperature $T_{\mathrm{c}}$ of the air outlet is obtained as follows:

$$
G_{1}(\mathrm{~s})=\frac{T_{\mathrm{h}}(s)}{T_{c}(s)}=\frac{K}{T s+1}
$$




\subsection{Laboratory humidity object model}

Similarly, the indoor humidity balance equation is obtained according to the quality of conservation:

$$
\rho V \frac{\mathrm{d}\left(\mathrm{d}_{n}\right)}{d t}=G_{a} \rho d_{c}+D_{n}-G_{\mathrm{a}} \rho \mathrm{d}_{\mathrm{n}}
$$

Where $\rho\left(\mathrm{kg} / \mathrm{m}^{3}\right)$ is air density, $\mathrm{V}\left(\mathrm{m}^{3}\right)$ is volume of laboratory, $\mathrm{d}_{n}(\mathrm{~g} / \mathrm{kg})$ is humidity of laboratory, $\mathrm{d}_{\mathrm{c}}(\mathrm{g} / \mathrm{kg})$ is degree of humidity in wind, $D_{n}(\mathrm{~g} / \mathrm{s})$ is moisture gain from Humidification material in laboratory. finally being:

$$
\begin{aligned}
& T_{1} \frac{\mathrm{d}(\underset{n}{\mathrm{~d}})}{\mathrm{dt}}+\mathrm{d}_{n}={ }_{c} \mathrm{~d}+d_{f} \\
& T_{1}=\frac{V}{G_{\mathrm{a}}} \quad, \quad \mathrm{d}_{\mathrm{f}}=\frac{D_{\mathrm{n}}}{G_{\mathrm{a}} \rho}
\end{aligned}
$$

Where $T_{1}$ is Time constant of humidity, $d_{f}$ is used to convert wet interference to degree of humidity change in wind.

The transfer function of the temperature $T_{\mathrm{h}}$ of the return air intlet and the temperature $T_{\mathrm{c}}$ of the air outlet is obtained as follows:

$$
G_{2}(\mathrm{~s})=\frac{\mathrm{d}_{\mathrm{n}}(s)}{\mathrm{d}_{c}(s)}=\frac{1}{T_{1} s+1}
$$

\subsection{Electric heater model}

There are eight groups of electric heaters in the test room (each group of about $60 \mathrm{~kW}$ ), three groups for analog control, and the other five for switch control. Electric heater has the characteristics of hysteresis and inertia, and its heating is a one-way process, that is, electric heating can only be cooled naturally. Regardless of the time delay and time variability of the electric heating, the transfer function between the heater's air outlet temperature and the electric heating power is simplified according to the energy balance equation to be:

$$
G_{3}(\mathrm{~s})=\frac{T_{\mathrm{c}}(s)}{P_{d}(s)}=\frac{K_{d}}{T_{d} s+1}
$$

\subsection{Surface air cooler model}

In actual control, the temperature of the chilled water flowing into the surface air cooler are controllable and set based on the temperature and humidity of the laboratory to ensure the effects of trial cooling, based on which the flow is controlled and the control over the temperature of the humid room. The differential equation of the heat exchanger is: 


$$
C V_{1} \rho_{1} \frac{d T_{\text {out }}}{d t}=C \rho_{1} W\left(T_{\text {out }}-T_{\text {in }}\right)+\beta A_{1}\left(T_{c}-T_{\text {out }}\right)
$$

Where $C\left(K J /\left(K g *{ }^{\circ} C\right)\right)$ is constant pressure specific heat of chilled water, $V\left(m^{3}\right)$ is volume of chilled water, $T_{\text {out }}\left({ }^{\circ} \mathrm{C}\right)$ is outlet water temperature, $\rho\left(\mathrm{Kg} / \mathrm{m}^{3}\right)$ is density of chilled water, $W\left(m^{3} / h\right)$ is flow, $T_{i n}\left({ }^{\circ} \mathrm{C}\right)$ is water inlet temperature, $A_{1}\left(m^{2}\right)$ is heat transfer surface areas of air cooler, $\beta\left(K J /\left(\mathrm{m}^{2} *{ }^{\circ} C\right)\right)$ is heat transfer coefficient.

\subsection{Humidifier model}

To control the steam flow into the laboratory with the electric valve on the humidifier can realize the air humidification of the laboratory, and the relationship between steam valve opening and the humidity by the humidifier presented with the first-order model:

$$
G_{4}(\mathrm{~s}) \frac{\mathrm{d}_{c}(s)}{W(s)}=\frac{K_{2}}{T+s}
$$

Through the analysis on the above model, the control output volume of humidity-heat test is the temperature $T_{\mathrm{h}}$ and the relative humidity of the test room, and the control input volume is the input power of the heater and the valve opening of the chilled water entering the cooler, the temperature of the chilled water and the opening of the steam humidification valve. The structure of the temperature and humidity control in humidity-heat test is as shown in Figure 1.

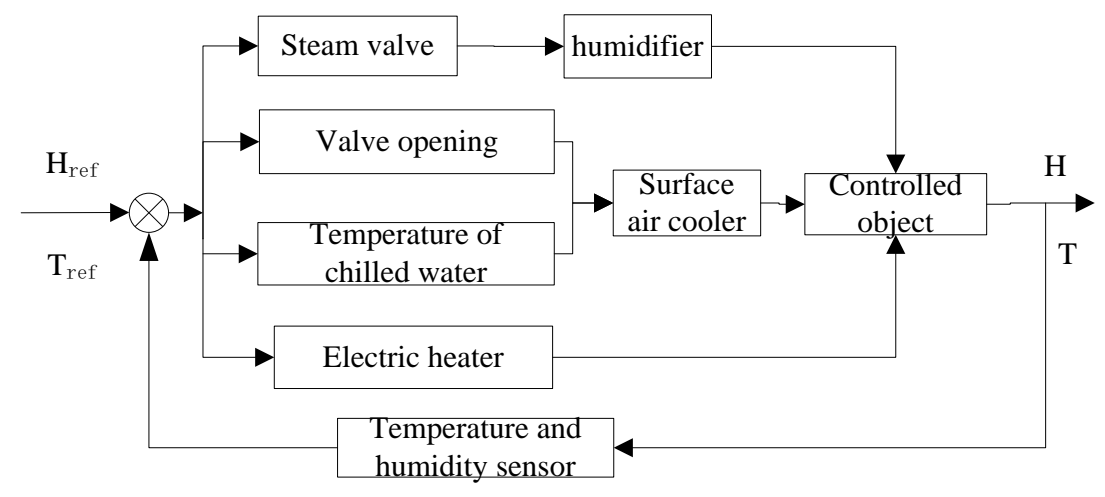

Fig. 1.The structure of the temperature and humidity control

\section{Control Requirements Over Temperature and Humidity}

According to the national standard GJB150.9A-2009 requirements for the humidity-heat test[4], Figure 2 is the temperature curve set by the humidity-heat test, which requires humidity to be reduced to $85 \%$ at the temperature reducing stage in the figure, and the relative humidity at all the other time must be guaranteed at $95 \% \pm 5 \%$. The humidity-heat alternative test takes a cycle of 24 hours, at least 10 cycles, and in general it can show the potential impact of the hot and humid environment on most equipment. 


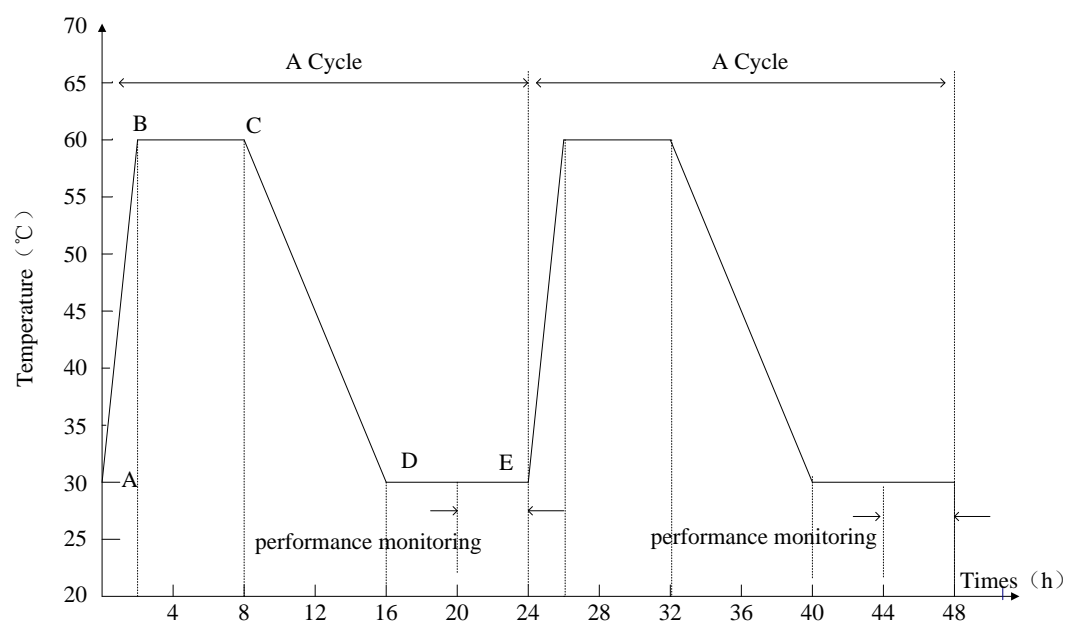

Fig. 2. The temperature curve set by the humidity-heat test

\section{Realization of Expert System in Multi-Variable System of Temperature and Humidity}

\subsection{Expert control system}

The architecture of expert control systems is shown in Fig.3. It consists of a knowledge base, a feature recognition, an inference engine and so on[5]. The knowledge base stores the rule models, steady state mathematical models, empirical knowledge, and operating laws for the process, etc[6-9]. The functions of feature recognition are processing online information, extracting and recognizing the characteristic information, and providing useful information for the decision-making procedure of the knowledge base and inference engine[10]. The task of the inference engine is to solve problems by using a certain reasoning strategy.

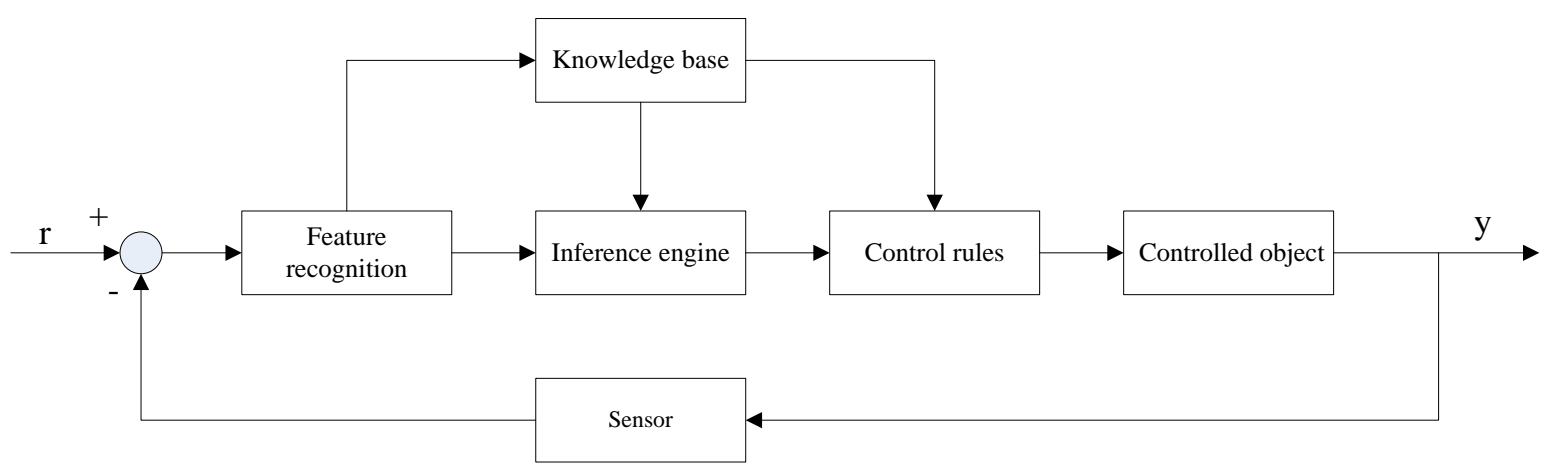

Fig. 3 The architecture of expert control system 


\subsection{Expert control strategy}

\subsubsection{Expert control over chilled water temperature}

The humidity-heat alternative test experiences different periods of time, so it shows varied requirements for temperature and it does not work to use chilled water of the same temperature[1112]. According to quite a few trials and comparisons on the spot, the following expert control scheme for chilled water is applied:

1)During the phase of the temperature curve rise (section A-B): The relative humidity of the test room changes due to the rising temperature of the laboratory. The control temperature of chilled water not only affects the temperature, but also indirectly influences the relative humidity in the laboratory. Therefore, the temperature rise phase is considered to be divided into several temperature zones. The rules are as follows:

$$
\begin{aligned}
& \text { If } T_{1}<36^{\circ} \mathrm{C} \text { Then } T_{2}=T_{1}-9^{\circ} \mathrm{C} ; \quad \text { If } 36^{\circ} \mathrm{C} \leq T_{1}<42^{\circ} \mathrm{C} \text { Then } T_{2}=T_{1}-8^{\circ} \mathrm{C} \text {; } \\
& \text { If } 42^{\circ} \mathrm{C} \leq T_{1}<48^{\circ} \mathrm{C} \text { Then } T_{2}=T_{1}-7^{\circ} \mathrm{C} ; \quad \text { If } 48^{\circ} \mathrm{C} \leq T_{1}<55^{\circ} \mathrm{C} \text { Then } T_{2}=T_{1}-6^{\circ} \mathrm{C} \text {; } \\
& \text { If } 55^{\circ} \mathrm{C} \leq T_{1}<60^{\circ} \mathrm{C} \text { Then } T_{2}=T_{1}-5^{\circ} \mathrm{C} \text {. }
\end{aligned}
$$

Where $T_{1}$ refers to indoor enactment temperature, $T_{2}$ is set temperature of chilled water.

2) In the equilibrium stage of $60^{\circ} \mathrm{C}$ (section $\mathrm{B}-\mathrm{C}$ ): since the temperature of the laboratory at this stage is set high, and the requirements for humidity are also high, the temperature can meet the requirements, but humidity cannot if the chilled water of great low is used to cool, because the effect of this chilled water of a temperature lower than that of the laboratory is equivalent to dehumidification, significantly reducing the humidity of the laboratory. So at this stage, the chilled water should be set not too high nor too low, because a too high temperature cannot reduce the temperature of the laboratory, and a too low one will reduce the humidity of the laboratory. Based on the summaries, a suitable temperature should be $T_{2}=T_{1}-4.5^{\circ} \mathrm{C}$.

3) In the phase of the temperature curve descending (section C-D): the control method at the temperature curve descending is similar to that at the rising phase. It is also divided into several temperature grades, and different temperatures of chilled water in different temperature grades are set as follow:

$$
\begin{aligned}
& \text { If } 56^{\circ} \mathrm{C} \leq T_{1}<60^{\circ} \mathrm{C} \text { Then } T_{2}=T_{1}-5^{\circ} \mathrm{C} \text {; } \quad \text { If } 50^{\circ} \mathrm{C} \leq T_{1}<56^{\circ} \mathrm{C} \text { Then } T_{2}=T_{1}-6^{\circ} \mathrm{C} \text {; } \\
& \text { If } 44^{\circ} \mathrm{C} \leq T_{1}<50^{\circ} \mathrm{C} \text { Then } T_{2}=T_{1}-7^{\circ} \mathrm{C} \text {; } \quad \text { If } 36^{\circ} \mathrm{C} \leq T_{1}<44^{\circ} \mathrm{C}, \quad T_{2}=T_{1}-8^{\circ} \mathrm{C} \text { : } \\
& \text { If } 30^{\circ} \mathrm{C} \leq T_{1}<36^{\circ} \mathrm{C} \text { Then } T_{2}=T_{1}-9^{\circ} \mathrm{C} \text {. }
\end{aligned}
$$

4)In the equilibrium stage of $30^{\circ} \mathrm{C}$ (section D-E): Due to the relatively low temperature at this stage, the relative humidity of the test room is much higher than before, and the the humidity is hardly impacted by temperature, taking $T_{2}=T_{1}-10^{\circ} \mathrm{C}$. 


\subsubsection{Expert control over chilled water flow}

According to the temperature of the return air inlet and the set PID, the chilled water valve opening is adjusted to control the chilled water flow. When the set temperature is higher than that of the return air inlet, the valve has to be reduced or closed, and vice versa. In the system debugging, it is found that the effect of chilled water flow (valve opening) on the temperature of the return air inlet is very obvious. On one hand, the chilled water flow, too large or too small, has an important effect on the temperature inside the test room, with marked hysteresis. On the other hand, the opening range of chilled water valve controlled and adjusted by the PID is $0 \%$ to $100 \%$, a wide range of control. It is found that in the actual control the limit of chilled water valve opening has something to do with the actual temperature of chilled water. After several times on-site commissioning, it can be summarized as follows:

If $0<\Delta \leq 5$ and temperature is in the phase of the curve rise (section $\mathrm{A}-\mathrm{B}$ ), Then $\phi=80 \%$. If $0<\Delta \leq 5$ and temperature is in the phase of the curve descending (section C-D), Then $\phi=33.3 \%$. If $5<\Delta \leq 10$ and temperature is in the phase of the curve rise (section A-B), Then $\phi=33.3 \%$. If $5<\Delta \leq 10$ and temperature is in the phase of the curve descending (section C-D), Then the maximum of $\phi$ is $25 \%$. If $\Delta>10$ Then $\phi=(32-\Delta / 2) \%$.

Where $T_{1}$ refers to indoor enactment temperature, $T_{3}$ is actual temperature of chilled water, $\phi$ is the degree of valve, $\Delta=\mathrm{T}_{1}-T_{3}$.

\subsubsection{Expert control over steam flow}

1) In the section $A B$ of the humidity-heat alternative curve: the test goes into the initial stage of the cycle (temperature set as $\mathrm{T} 1<40^{\circ} \mathrm{C}$ ). Since the set temperature is not very high, and the humidity easily rises to the set value, the conventional PID is adopted to regulate the opening degree of steam valve. With the set temperature and the actual temperature continually rising, the humidity increasing somewhat hard, the front feed + PID algorithm is adopted at the second half of the curve rise $(40 \leq \mathrm{T} 1$ $<60^{\circ} \mathrm{C}$ ). The valve opening is added to one more front feed on the basis of PID adjustment. The front feed amount is determined in accordance with the difference between the set humidity and the actual humidity, and the greater the difference the greater the amount of feed forward.

2) In the section B-C of the curve: This section shows the highest temperature during the whole process. According to the principle that the higher the temperature the lower the relative humidity, which shows the greatest difficulty in rising, so the steam valve has been in full opening.

3 ) In the descending phase of the curve, as the temperature continues to decline, the relative humidity is rising steadily. The conventional PID control is largely applied in this phase.

\section{Control results}

Figure 4 is the temperature-humidity curve controlled with conventional algorithms. In the whole process, the set temperature of chilled water is always $T_{2}=T_{1}-10^{\circ} \mathrm{C}$, the steam flow is controlled by 
PID, and it can be seen that in the stage of $60^{\circ} \mathrm{C}$, the laboratory humidity is lower than $85 \%$ for quite a long time, and humidity of other stages is not very stable as well. Figure 5 is the temperaturehumidity curve of humidity-heat alternative test with expert control algorithm, and it can be seen from it that in the phase of temperature curve rising, the relative humidity can quickly rise up to $95 \%$, but with the temperature rising, the relative humidity significantly reduces; at $60{ }^{\circ} \mathrm{C}$ when the steam valve is opened to the maximum, the relative humidity gradually increases to $95 \%$; in the curve down stage, due to the continuous decline of temperature, the humidity is controlled with PID at about $90 \%$. When the temperature reaches the stable stage of $30^{\circ} \mathrm{C}$, the relative humidity can be well controlled at about $93 \%$. By comparison, it can be implied that the control precision by expert control has been greatly improved than the traditional control algorithm.

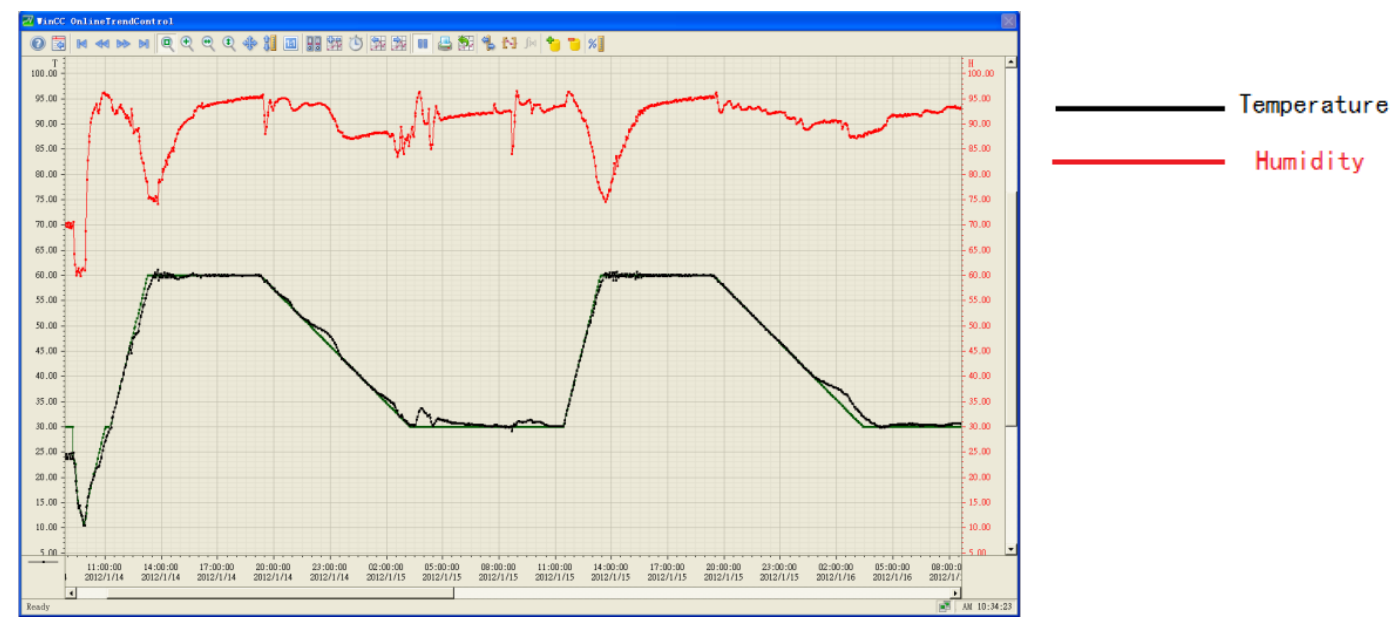

Fig. 4. The temperature-humidity curve controlled with conventional algorithms

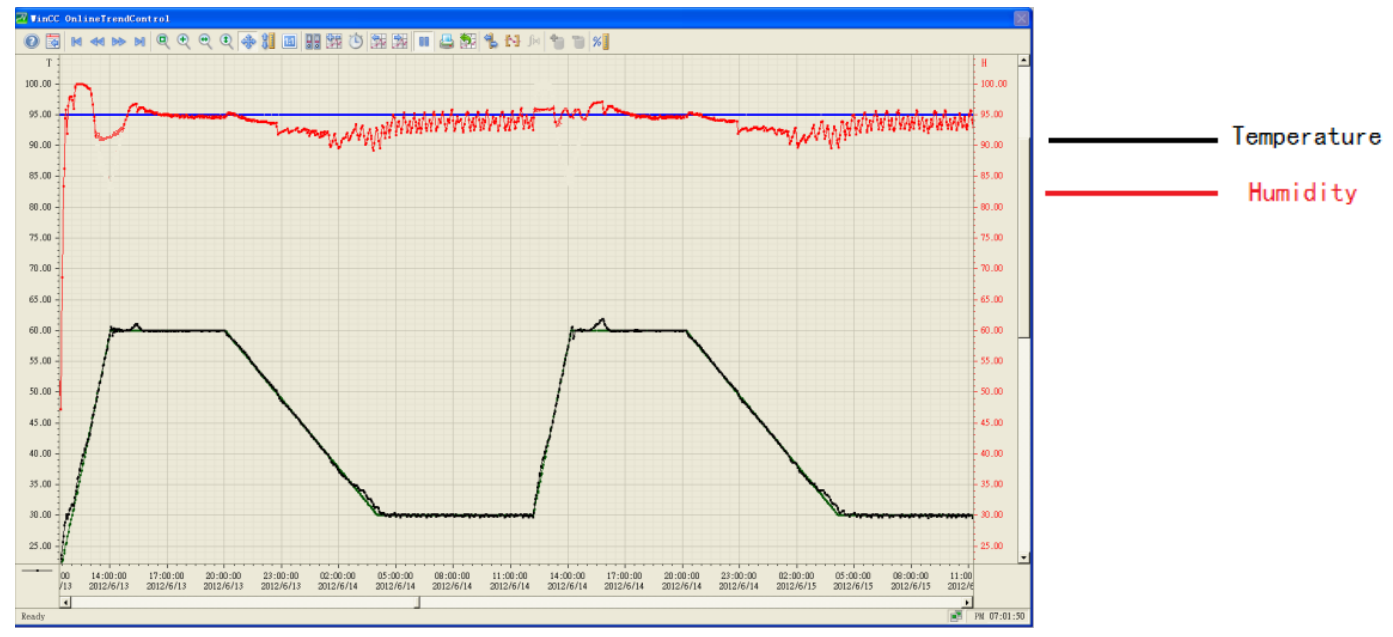

Fig. 5. The temperature-humidity curve controlled with expert control algorithm

\section{Conclusion}

This paper, based on the actual engineering project and combined with the characteristics of the humidity-heat alternative test, takes the temperature and humidity as the control variables, applies the expert control system, and adopts PLC as the control platform to perform the experiment, using 
advantages of PLC like great reliability, flexibility and adaptability while greatly improving the control precision of strong coupling and non-linear parameters. It has been proved that this control system has the advantages of the conventional control algorithm and shows great control quality in speeding up the control response time, reducing oscillation and stabilizing errors.

\section{References}

[1] Shi X, Zhu N, Zheng G. The combined effect of temperature, relative humidity and work intensity on human strain in hot and humid environments[J]. Building \& Environment, 2013, 69(11):72-80.

[2] Mukaidani H. An LMI approach to decentralized guaranteed cost control for a class of uncertain nonlinear large-scale delay systems[J]. Journal of Mathematical Analysis \& Applications, 2004, 300(1):17-29.

[3] Ghaffari V, Naghavi S V, Safavi A A. Robust model predictive control of a class of uncertain nonlinear systems with application to typical CSTR problems[J]. Journal of Process Control, 2013, 23(4):493-499.

[4] Lewis G, Coulson M, Vergnet C, et al. Proposed revision of the higher tier testing requirements for EPPO standard PP1/170: test methods for evaluating the side-effects of plant protection products on honeybees.[J]. Julius-Kühn-Archiv, 2010(423):34-42.

[5] Pernell K, Jung J, Dobbin F. The Hazards of Expert Control: Chief Risk Officers and Risky Derivatives[J]. American Sociological Review, 2017, 82(3):511-541.

[6]Lasso E, 脫 scar Valencia, Corrales J C. Decision Support System for Coffee Rust Control Based on Expert Knowledge and Value-Added Services[C]// International Conference on Computational Science and Its Applications. Springer, Cham, 2017:70-83.

[7] Du M. Legal control of expert witness bias[J]. 2017, 21(1-2):69-78.

[8] Arakaki J, Miyagi P E. Degeneration Methods in Intelligent Building Control System Design[J]. Information Technology for Balanced Manufacturing Systems, 2006, 220:469-478.

[9] Rt M Y R G. Knowledge elicitation for fuzzy rule based decision support systems and system interface evaluation and design.[J].

[10] Evans M, Kennedy J. Integration of Adaptive Neuro Fuzzy Inference Systems and principal component analysis for the control of tertiary scale formation on tinplate at a hot mill[J]. Expert Systems with Applications, 2014, 41(15):6662-6675.

[11] Schwedler M, Bakkum B. Upgrading chilled-water systems[J]. Ashrae Journal, 2009, 51(11):1632.

[12] Sarkar M. Simplified thermodynamic modeling of chilled water coils based on bypass factors[J]. Energy \& Buildings, 2015, 103(3-4):384-395. 